\title{
Estimation of Water Retention Curve for Soils of Bahia, Brazil, Based on Soil Particle-Size Analysis
}

\author{
Felipe Gomes Frederico da Silveira ${ }^{1}$, Luciano da Silva Souza ${ }^{2}$, Laércio Duarte Souza ${ }^{3}$, \\ João de Mendonça Naime ${ }^{4} \&$ Carlos Manoel Pedro Vaz ${ }^{4}$ \\ ${ }^{1}$ Department of Agricultural and Environmental Sciences, Universidade Estadual de Santa Cruz, Ilhéus, BA, \\ Brazil \\ ${ }^{2}$ Center for Agricultural, Environmental, and Biological Sciences, Universidade Federal do Recôncavo da Bahia, \\ Cruz das Almas, BA, Brazil \\ ${ }^{3}$ Embrapa Cassava and Fruits, Cruz das Almas, BA, Brazil \\ ${ }^{4}$ Embrapa Instrumentation, São Carlos, SP, Brazil \\ Correspondence: Felipe Gomes Frederico da Silveira, Potsgraduate Program in Plant Production, Center for \\ Agricultural, Environmental, and Biological Sciences, Universidade Estadual de Santa Cruz, Rodovia Jorge \\ Amado, km 16, 45662-900, Ilhéus, BA, Brazil. E-mail: felipegomes87@hotmail.com
}

Received: August 6, 2018

doi:10.5539/jas.v10n12p126
Accepted: September 6, $2018 \quad$ Online Published: November 15, 2018

URL: https://doi.org/10.5539/jas.v10n12p126

\begin{abstract}
Soil water retention curve (SWRC) is an important soil attribute because it is a soil quality indicator and is fundamental to study water dynamics in the soil-plant-atmosphere system. Since the conventional SWRC determination is laborious and time-consuming, making it difficult to process a large volume of samples, pedotransfer functions have been used to estimate it by using other soil physical attributes easily determined. Thus, this study aimed to apply Arya-Paris model to SWRC estimation for soils of Bahia state, Brazil, based on soil particle-size analysis, and to compare estimated and determined data of SWRC. Samples were collected from horizons $\mathrm{A}$ and $\mathrm{AB}$ and/or B and/or C, for a total of 15 soils and 62 horizons. Particle-size was determined by automatic soil particle-size analyzer (PSA) based on $\gamma$-ray attenuation and traditional Bouyoucos' hydrometer (BH) method. Arya-Paris model showed better SWRC predictions for sandy soils, followed by clayey, loamy, and very clayey soils. Good model performance was observed for all soils together. The $\alpha 1$ scaling factor provided better predictions, followed by $\alpha 3$, and $\alpha 2$ showed unsatisfactory behavior. BH method, using only 7 soil particle-size fractions, gave slightly higher predictions than PSA using 30 soil particle-size fractions.
\end{abstract}

Keywords: soil water retention curve, Arya-Paris model, automatic soil particle-size analyzer, Bouyoucos' hydrometer method.

\section{Introduction}

Soil water retention curve (SWRC) expresses the relationship between soil moisture and matric potential (Vieira, 2007) and is an excellent soil physical indicator; however, it is difficult to characterize because of both the time of analysis consumed and the intrinsic influence of hysteresis (Nascimento, Bassoi, \& Paz, 2012).

SWRC evaluation is essential for estimation of plant available water (Mohammadi, Asadzadeh, \& Vanclooster, 2010), of water infiltration capacity (Carrick, Buchan, Almond, \& Smith, 2011), and of drainage and solute movement (Mohammadi, Neishabouri, \& Rafahi, 2009; Mohammadi \& Vanclooster, 2011). However, SWRC direct measurement is laborious, time-consuming, and subject to several errors. Thus, many researchers have presented several indirect methods to obtain SWRC (Mohammadi \& Meskini-Vishkaee, 2013).

Arya and Heitman (2015) consider SWRC indirect estimation as preferable over the direct measurement, because the measured data are subject to errors and uncertainties due to natural variability, sampling errors, sample preparation methods, and variations in the experimental procedures.

Specifically for soil water retention capacity estimation, mathematical models based on relatively simple data, such as soil particle-size distribution, soil bulk density, particle density, organic matter, and other basic attributes, are used (Arya, Van Genutchen, \& Shouse, 1999; Pachepsky \& Rawls, 1999). 
Particle-size distribution is considered as one of the most fundamental soil physical properties, expressed as clay, silt, and sand percentages. These three fractions directly influence soil properties such as water retention curve, available water capacity, saturated hydraulic conductivity, thermal conductivity, and adsorption properties of chemical substances (D. Wang, Zhao, Hu, \& Y. F. Wang, 2008, Minasny \& Hartemink, 2011, Botula, Cornelis, Baert, Mafuka, \& Ranst, 2013).

Arya and Paris (1981) proposed a SWRC estimation model based on the similarity between soil particle-size distribution and water retention curve. Since then, the interest in this model has been constant because it provides a method to transform particle-size distribution into a continuous and complete SWRC (Matula, Mojrova, \& Spongrova, 2007; Nimmo, Herkelrath, \& Laguna Luna, 2007; Sepaskhah \& Raifee, 2008; Chiu, Yan, \& Ka, 2012; Fooladmand \& Habibi, 2012; Meskini-Vishkaee, Mohammadi, \& Vanclooster, 2014).

Thus, the Arya and Paris (1981) model uses the similarity between the functions that describe particle-size distribution and SWRC to indirectly obtain the latter function. Pore size is associated to a certain pore volume determined by the scaling technique (Arya, Van Genutchen, \& Shouse, 1999).

In previous work Vaz, Naime, and Silva (2005) evaluated Arya and Paris (1981) model applicability for a set of 104 soil samples from São Paulo and Rio Grande do Sul states, Brazil, and using 30 soil particle-size fractions determined by automatic soil particle-size analyzer (PSA) based on $\gamma$-ray attenuation. The present study aims to analyze Arya and Paris (1981) model feasibility to estimate SWRC for soils of Bahia state, Brazil, based on soil particle-size analysis determined by the same methodology and by traditional Bouyoucos' hydrometer (BH) method, which determines only 7 soil particle-size fractions, and to compare with determined SWRC data. In addition to evaluating different soils, this is the major difference of this study, in which the Arya and Paris (1981) model feasibility to estimate SWRC occurred using only 7 soil particle-size fractions, while Vaz, Iossi, Naime and Silva (2005) used 30 soil particle-size fractions.

\section{Material and Methods}

The study was performed on using soil samples with different physical and morphological characteristics, collected in 14 different locations of Bahia state (Amargosa, Cruz das Almas, Gandu, Itabela, Itamaraju, Lapão, Nova Soure, Prado, Porto Seguro, Ribeira do Amparo, Rio Real, Souto Soares, Ubaíra, and Una) and with different textural classes. Samples of horizons A and AB, and/or B, and/or C, in a total of 15 soils and 62 horizons were collected. The soils collected were: (a) sandy: Latossolo Amarelo (Ferralsol; Oxisol), Latossolo Vermelho-Amarelo (Ferralsol; Oxisol), and Neossolo Quartzarênico (Arenosol; Entisol); (b) loamy: Argissolo Vermelho-Amarelo (Acrisol; Ultisol) and Latossolo Amarelo; (c) clayey: Argissolo Amarelo (Acrisol; Ultisol), Argissolo Vermelho-Amarelo, Cambissolo Háplico (Cambisol; Inceptisol), Latossolo Amarelo, Latossolo Vermelho-Amarelo, and Latossolo Vermelho (Ferralsol; Oxisol); and (d) very clayey: Argissolo Vermelho-Amarelo, Latossolo Vermelho-Amarelo, and Latossolo Vermelho. All soils are kaolinitic and the structure varies from simple grains, weak small to large granular and weak small to medium subangular blocks in sandy soils; weak small subangular blocks in loamy soils; weak very small to small granular, moderate to strong medium to large granular, weak to moderate small to medium subangular blocks in clayey soils; and small lumps with porous massive appearance "in situ" and weak small to medium subangular blocks, in very clayey soils. The evaluated soils are representative of Bahia state and have significant agricultural importance, being mainly cultivated with citrus, papaya, pineapple, melon, coffee, cocoa, guarana, cupuaçu, rubber tree, cassava, tobacco, castor bean, pasture, and other crops. SWRC knowledge is important for these crops management.

Physical analyses were performed at Soil Physical Laboratory of Embrapa Cassava and Fruits, in the municipality of Cruz das Almas, in Bahia state, according to Donagema, Campos, Calderano, Teixeira, and Viana (2011) methods, except for particle-size analysis obtained by grain size analyzer, which was performed at Embrapa Instrumentation, in São Carlos, São Paulo.

Particle-size analysis was performed by two different methods. The first one was the automatic particle-size analyzer (PSA) based on gamma radiation attenuation by scattered particles in sedimentation was utilized (Naime, Vaz, \& Macedo, 2001), after chemical dispersion with sodium hydroxide plus mechanical shaking for 15 minutes at 12,000 r.p.m. This technique allows to separate 30 soil particle-size fractions. Results were recorded in file containing cumulative concentration data, in percentage of the initial concentration and particle diameter $(\mu \mathrm{m})$. Analyzer measurements were made in triplicate and the average value was considered. This same methodology was used by Vaz, Iossi, Naime, and Silva (2005). The second one was the Bouyoucos' hydrometer method using the same kind of dispersion as above, and the total sand fraction separated into five fractions: very coarse sand $(2.00-1.00 \mathrm{~mm})$, coarse sand $(1.00-0.50 \mathrm{~mm})$, medium sand $(0.50-0.25 \mathrm{~mm})$, fine sand $(0.25-0.10$ 
$\mathrm{mm})$, and very fine sand $(0.10-0.05 \mathrm{~mm})$, besides silty $(0.05-0.002 \mathrm{~mm})$ and clay $(<0.002 \mathrm{~mm})$. Textural classification was obtained by texture triangle (Donagema, Campos, Calderano, Teixeira, \& Viana, 2011).

Volumetric cylinder method was utilized to determine soil bulk density by collecting, in each soil profile horizons, two undisturbed soil samples packed in Uhland sampler with approximately $310 \mathrm{~cm}^{3}$ volume; arithmetic average of two replications was considered for results comparison. Particle density was obtained through the volumetric flask method by using ethanol as penetrating liquid (Donagema, Campos, Calderano, Teixeira, \& Viana, 2011), and total porosity was obtained by calculation, according to the following expression:

$$
T P=\frac{\rho_{p}-\rho_{s}}{\rho_{s}}
$$

where, $T P$ is the calculated total porosity $\left(\mathrm{m}^{3} \mathrm{~m}^{-3}\right), \rho_{p}$ is soil particle density $\left(\mathrm{kg} \mathrm{dm}^{-3}\right)$, and $\rho_{s}$ is soil bulk density $\left(\mathrm{kg} \mathrm{dm}^{-3}\right)$.

SWRC was experimentally obtained in laboratory by using tension table and Richards' pressure chambers (Richards, 1949), and estimated by Arya and Paris (1981) model by using soil particle-size data, according to Vaz, Iossi, Naime, and Silva (2005).

Undisturbed soil samples were collected in metal cylinders with approximately $100 \mathrm{~cm}^{3}$ volume to determine SWRC in laboratory. These samples were slowly saturated by capillarity for 24 hours and subjected to $6 \mathrm{kPa}$ tension on a tension table and to pressures of 10,33,100,300, and 1,500 kPa in the Richards' pressure chambers (Richards, 1949). The soil moisture related to each tension and pressure was determined by drying samples in an oven at $105^{\circ} \mathrm{C}$ for 48 hours.

The Van Genuchten (1980) model was fitted to moisture and matric potential values provided by water retention analysis in the laboratory using the program SWRC (Dourado-Neto, Nielsen, Hopmans, Reichardt, \& Bachi, 2000):

$$
\theta=\theta_{r}+\frac{\theta_{s}-\theta_{r}}{\left[1+\left(\alpha\left|\phi_{m}\right|\right)^{n}\right]^{m}}
$$

where, $\theta=$ soil moisture, in $\mathrm{m}^{3} \mathrm{~m}^{-3} ; \theta_{r}=$ residual moisture, in $\mathrm{m}^{3} \mathrm{~m}^{-3} ; \theta_{s}=$ saturation moisture, in $\mathrm{m}^{-3} \mathrm{~m}^{-3} ; \phi_{m}=$ soil water matric potential; and $\alpha, n$, and $m$ are fitting coefficients.

Soil physics has fundamental principles for soil-water relationship understanding. Arya and Paris (1981) model is based on two of these principles. The first one is the capillarity equation, which relates soil water matric potential $\left(\phi_{\mathrm{m}}\right)$, expressed by the capillary rise height, and pore diameter:

$$
\phi_{m}=\frac{2 \sigma \cdot \cos \alpha}{\rho_{w} g r_{i}}
$$

where, $\sigma\left(0.0728 \mathrm{~N} \mathrm{~m}^{-1}\right)$ is the water surface tension in the water-air interface; $\theta$ is the contact angle (considered near to zero, therefore $\cos \alpha=1) ; \rho_{w}\left(\mathrm{~kg} \mathrm{~m}^{-3}\right)$ is the water density; $g\left(9.81 \mathrm{~m} \mathrm{~s}^{-2}\right)$ is the gravity acceleration; and $r_{i}(\mathrm{~m})$ is the pore radius, considering the international system of units (SI).

The second principle is the soil particle-size distribution and the contribution of each fraction to soil water saturation:

$$
\theta_{i}=\left(1-\frac{\rho_{s}}{\rho_{p}}\right) \sum_{i=1}^{i=n} w_{i}
$$

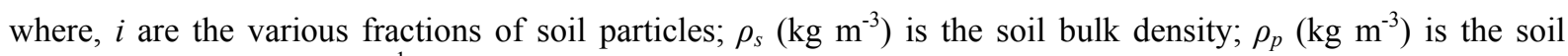
particle density; and $w_{i}\left(\mathrm{~g} \mathrm{~g}^{-1}\right)$ is the fraction of soil mass given by the particle-size distribution curve.

The connection between Equations (3) and (4) for SWRC estimation by Arya and Paris (1981) model is performed by associating the pore radius $\left(r_{i}\right)$ and particle radius $\left(\mathrm{R}_{\mathrm{i}}\right)$ through the following equation:

$$
r_{i}=R_{i} \frac{\sqrt{4 e n_{i}^{(1-\alpha)}}}{6}
$$

where, $n_{i}$ is the number of spherical particles of $i$-th class of soil mass; and $e$ is the void ratio obtained by:

$$
\begin{gathered}
n_{i}=\frac{3 w_{i}}{4 \pi R_{i}^{3} \rho_{p}} \\
e_{i}=\frac{\rho_{p}-\rho_{s}}{\rho_{s}}
\end{gathered}
$$


The $\alpha$ (alpha) coefficient is defined as a scaling factor, which, according to Basile and D'Urso (1997), represents the empirical fit to pore tortuosity in soils under natural conditions. Arya and Paris (1981) consider 1.38 as the best estimate value for it. Arya and Dierolf (1992), mentioned by Vaz, Iossi, Naime and Silva (2005), obtained 0.938 for $\alpha$ scaling factor.

The soil matric potential is calculated by the combination of Equations 3, 5, 6, and 7:

$$
\phi_{i}=\frac{2 \sigma}{\rho_{w} g R_{i} \sqrt{\frac{w_{i}\left(\rho_{p}-\rho_{s}\right)}{2 \pi R_{i}^{3} \rho_{s} \rho_{p}}}}
$$

This study utilized the following equations to analyze the $\alpha$ scaling factor:

$$
\begin{gathered}
\alpha 1=0.947+0.427 e^{\left(\frac{\theta}{0.129}\right) \quad(\text { Vaz, Iossi, Naime, \& Silva, 2005) }} \\
\alpha 2=1-\log \left[\frac{3 \sigma}{\rho_{w} \psi_{i} g R_{i}}\right] \quad \text { (Vaz et al., 2005) } \\
\alpha 2=\frac{\log N_{i}}{\log n_{i}} \quad \text { (Arya, Van Genutchen, \& Shouse, 1999) }
\end{gathered}
$$

where, $n_{i}$ is the number of spherical particles of $\mathrm{i}$-th class of soil mass, described by Equation (6), and $\mathrm{N}_{\mathrm{i}}$ is the number of spherical particles necessary to estimate the pore length in the soil natural structure, equal to:

$$
N_{i}=7.371 \cdot w_{i} e \frac{\phi_{i}^{2}}{\rho_{s} R_{i}}
$$

Moisture and matric potential values were obtained using an Excel spreadsheet; then, the Genuchten (1980) model was fitted by means of the program SWRC (Dourado-Neto, Nielsen, Hopmans, Reichardt, and Bachi, 2000), according to Equation (2).

Three $\alpha$ scaling factors were used for Arya and Paris (1981) model application, which are described in Equations (9), (10), and (11).

As three different alpha scaling factors were utilized to estimate moisture: $\alpha 1$ (Vaz et al., 2005); $\alpha 2$ (Vaz et al., 2005); and $\alpha 3$ (Arya et al., 1999), and as these scaling factors provided different moisture values, each set of moisture values was correlated with the moisture content obtained in laboratory by Richards (1949) method.

The comparison between moisture contents measured $\left(\theta_{\text {measured }}\right)$ and estimated $\left(\theta_{\text {estimated }}\right)$ by Arya and Paris (1981) model was performed through simple linear regression fit between the observed values and the estimated values $\mathrm{y}$, by using the 1:1 equation, where $y=a+b x$. The closer to 0 for $a$ and closer to 1 for $b$ coefficients, the higher the proximity between measured and estimated values. In this kind of relationship the accuracy is greater the lower the dispersion of points in relation to the 1:1 line, which represents a perfect adjustment.

Besides the simple linear regression fit evaluation, the comparison between moisture contents measured $\left(\theta_{\text {measured }}\right)$ and estimated $\left(\theta_{\text {estimated }}\right)$ by Arya and Paris (1981) model was performed using the square root of the mean square error (RMSE) based on the following equation:

$$
R M S E=\sqrt{\frac{\sum_{i=1}^{i=n}\left(\theta_{\text {measured }}-\theta_{\text {estimated }}\right)^{2}}{n}}
$$

The smaller the RMSE the greater the proximity between measured and estimated values.

\section{Results and Discussion}

\subsection{Soil Physical Properties}

The soil particle-size analysis allowed the observation of 10 out of 13 textural classes present in the texture triangle, ranging from sandy to clayey (Figure 1); only loam, silty-loam, and silty particle-size classes were not found in the evaluated soils. 


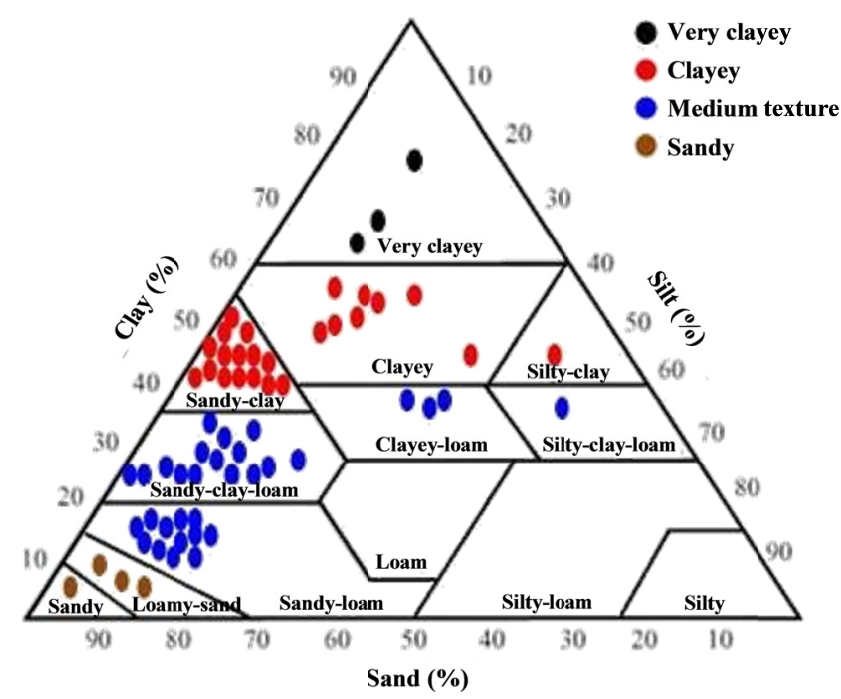

Figure 1. Particle-size classes of sampled and evaluated soils

\subsection{1:1 Moisture Graphics}

Figures 2 to 6 show the result of the predictive capacity of AP model (PSA and BH) compared to measured values for four evaluated soil particle-size groups separately and together, and for three scaling factors $\alpha$ tested for both methods utilized to measure soil particle size. Tables 1 to 5 show fitting parameters for linear regressions between measured and estimated values, and RMSE for these same situations.

According to Arya, Bowman, Thapa and Cassel (2008) it is expected that the developed parameters for a given soil can be used for similar soils to obtain the SWRC; however, there is no certainty that there will be frequent similarity in the results.

\subsubsection{Sandy Soils}

In the R $\times$ AP correlations between values obtained in laboratory by Richards (1949) method (R), and the estimated values obtained by Arya and Paris (1981) model (AP) for soil particle-size analyzer (PSA) and Bouyoucos' hydrometer (BH) method (Figure 2), for sandy soils with different scaling factors, in general there were variations for PSA involving under- and overestimated values for $\alpha 1$ and $\alpha 3$ scaling factors in all the soil moisture range studied, with a higher frequency of overestimation in the driest range, especially when using alpha 3. As for $\alpha 2$ there was overestimation of the values for all moisture contents. In general, for BH there were under- and overestimated values for all scaling factors and in all moisture range, with a higher frequency in the driest range.

The values of $a$ coefficient and RMSE were closer to 0 and the $b$ coefficients were closer to 1 for $\alpha 1$ scaling factor, for both PSA and BH (Table 1), indicating good results of AP model in water retention prediction in sandy soils for this scaling factor.

Basile and D'Urso (1997) obtained good results with AP model for sandy soils, by using $\alpha$ equal to 1.38 and 0.938 , based on particle-size distribution (sand, silt, and clay) obtained by BH method.

The $\alpha 1$ coefficient was defined by Vaz, Iossi, Naime, and Silva (2005) as a water content function, representing a progress compared with fixed values of 1.38 and 0.938 considered respectively by Arya and Paris (1981) and Arya and Dierolf (1992) as the best estimates values for $\alpha 1$.

The discrepancy between data observed by relating AP and R methods (analyzer or hydrometer) can be assigned to the observation made by Urach (2007), who concluded that pedotransfer functions are more effective when utilized to estimate water retention in soils with similar characteristics to those used to generate the equations. On this matter, it is important to highlight that Arya and Paris (1981) model was developed using soils of temperate regions, while the evaluated soils in this study are from tropical regions and previously characterized herein. 

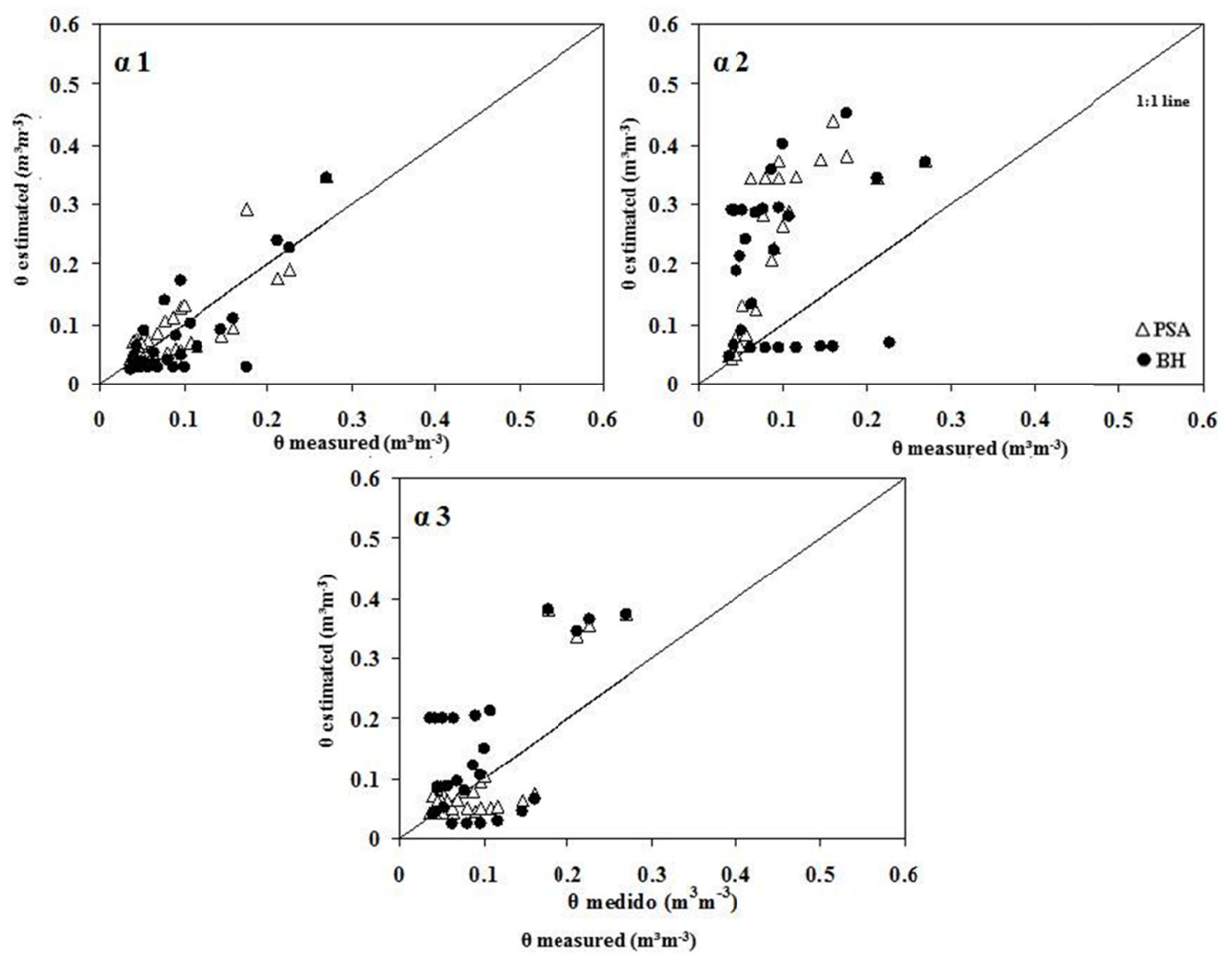

Figure 2. Relationship between measured moisture content $\left(\theta_{\text {measured }}\right) \times$ estimated moisture content $\left(\theta_{\text {estimated }}\right)$ by Arya and Paris (1981) model, based on particle-size analysis determined by the PSA and BH for different alpha scaling factors in sandy soils

Table 1. Comparison between measured and estimated moisture contents, analyzed by Arya and Paris (1981) model in sandy soils, based on soil particle-size data obtained by the PSA and BH for three alpha scaling factors evaluated

\begin{tabular}{|c|c|c|c|c|c|c|}
\hline \multirow{2}{*}{ Fitting parameters } & \multicolumn{3}{|c|}{ Particle-size analyzer (PSA) } & \multicolumn{3}{|c|}{ Bouyoucos hydrometer (BH) } \\
\hline & $\alpha 1$ & $\alpha 2$ & $\alpha 3$ & $\alpha 1$ & $\alpha 2$ & $\alpha 3$ \\
\hline Intercept & 0.00668 & 0.03881 & -0.03602 & -0.01698 & 0.17526 & 0.02185 \\
\hline Slope coefficient & 0.96337 & 2.03380 & 1.47003 & 1.01796 & 0.36060 & 1.21399 \\
\hline $\mathrm{R}^{2}$ & 0.6752 & 0.6425 & 0.7136 & 0.6468 & 0.0311 & 0.4382 \\
\hline $\operatorname{RMSE}^{(1)}$ & 0.041 & 0.178 & 0.064 & 0.048 & 0.172 & 0.095 \\
\hline
\end{tabular}

Note. ${ }^{(1)}$ Square root of the mean square error.

\subsubsection{Loamy Soils}

For loamy soils, in both PSA and BH, in AP $\times \mathrm{R}$ correlations (Figure 3), it was possible to observe the underestimated values of Arya and Paris (1981) model for $\alpha 1$ scaling factor in the driest range and the overestimated values for $\alpha 2$ in practically all moisture range; and for $\alpha 3$ it was possible to observe the overestimated values for both the lowest and highest moisture contents. 

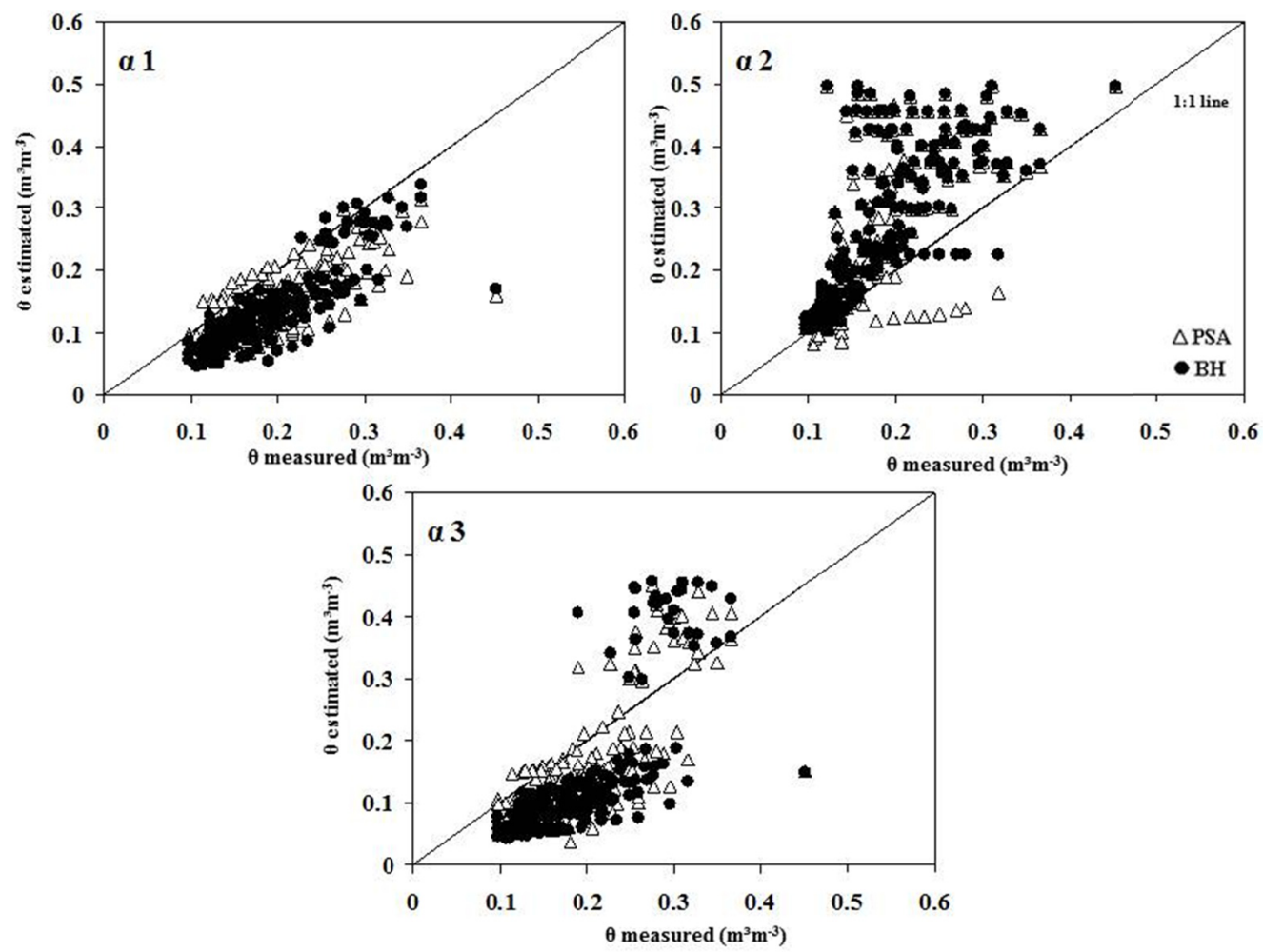

Figure 3. Relationship between measured moisture content $\left(\theta_{\text {measured }}\right) \times$ estimated moisture content $\left(\theta_{\text {estimated }}\right)$ by Arya and Paris (1981) model, based on particle-size analysis determined by the PSA and BH for different alpha scaling factors in loamy soils

Table 2. Comparison between measured and estimated moisture contents, analyzed by Arya and Paris (1981) model in loamy soils, based on particle-size analysis obtained by the PSA and BH for three alpha scaling factors evaluated

\begin{tabular}{|c|c|c|c|c|c|c|}
\hline \multirow{2}{*}{ Fitting parameters } & \multicolumn{3}{|c|}{ Particle-size analyzer (PSA) } & \multicolumn{3}{|c|}{ Bouyoucos hydrometer (BH) } \\
\hline & $\alpha 1$ & $\alpha 2$ & $\alpha 3$ & $\alpha 1$ & $\alpha 2$ & $\alpha 3$ \\
\hline Intercept & 0.01606 & 0.05615 & -0.05726 & -0.02557 & 0.05644 & -0.10814 \\
\hline Slope coefficient & 0.65204 & 1.16744 & 1.08006 & 0.84059 & 1.18297 & 1.27148 \\
\hline $\mathrm{R}^{2}$ & 0.5857 & 0.3826 & 0.5327 & 0.7025 & 0.4426 & 0.5432 \\
\hline $\operatorname{RMSE}^{(1)}$ & 0.067 & 0.132 & 0.078 & 0.068 & 0.127 & 0.095 \\
\hline
\end{tabular}

Note. ${ }^{(1)}$ Square root of the mean square error.

Although the $a$ coefficient and RMSE values are closer to 0 for $\alpha 1$ scaling factor, both in PSA and BH (Table 2), the $b$ value distanced itself from 1 , below, setting the overestimation condition. This was highlighted by the data obtained through PSA, with BH method showing therefore a better performance. Despite that, comparing the values of these three coefficients with three scaling factors evaluated, it can be assumed that the $\alpha 1$ scaling factor still behaved better than $\alpha 2$ and $\alpha 3$. This indicates that Arya and Paris (1981) model behavior in the water retention curve prediction for the evaluated loamy texture soils was less accurate than with sandy soils.

According to Hwang and Choi (2006), soils in natural conditions have aggregation of primary particles into secondary ones, root channels, and microcracks, factors that may increase pore distribution by size, and consequently, influence the estimation process of water retention curve by Arya and Paris model (1981). Possibly, because of this, Hwang and Choi (2006) reported that the difference between predicted and estimated water retention curves varies according to soil texture.

Basile and D'Urso (1997) obtained quite divergent values measured and estimated by the Arya and Paris (1981) model for soils of clayey-loam texture (loamy), both for $\alpha=1.38$ and $\alpha=0.938$. 


\subsubsection{Clayey Soils}

For clayey soils, as observed in medium texture soils, both in PSA and BH in AP $\times$ R correlations (Figure 4), it was possible to observe a higher occurrence of underestimation of the values for the $\alpha 1$ and $\alpha 3$ scaling factors in all moisture range, and mainly overestimation for $\alpha 2$ mainly in medium- and high-range moisture values.

By analyzing together the $a, b$ and RMSE coefficients (Table 3), it was possible to observe, once again, a better result of $\alpha 1$ scaling factor, especially for soil particle-size data obtained by BH method, followed by $\alpha 3$ and then by $\alpha 2$. The Arya and Paris (1981) model behavior in water retention curve prediction for clayey soil was better when compared to sandy and loamy soils.
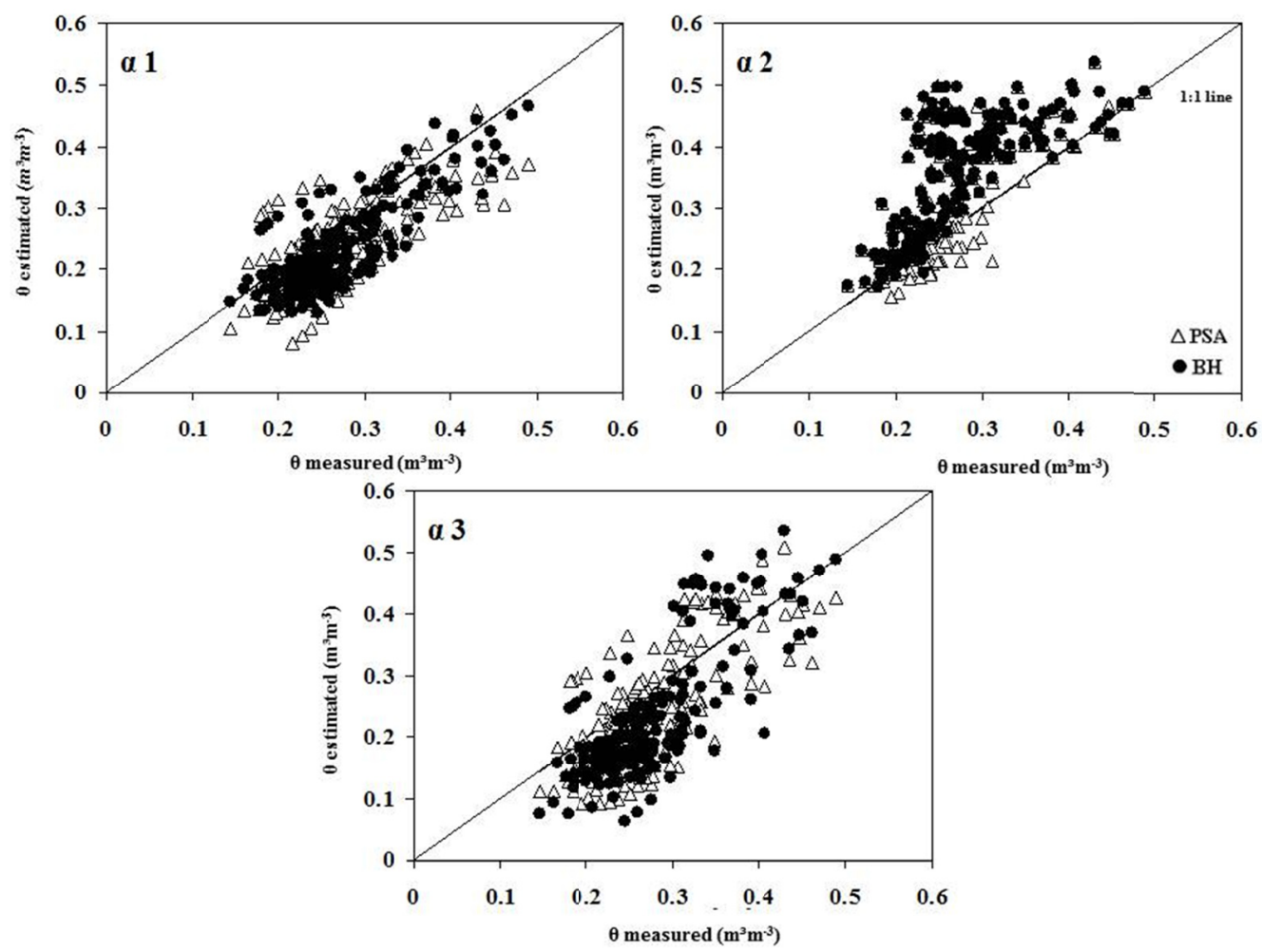

Figure 4. Relationship between measured moisture content $\left(\theta_{\text {measured }}\right) \times$ estimated moisture content $\left(\theta_{\text {estimated }}\right)$ by Arya and Paris (1981) model, based on particle-size analysis determined by the PSA and BH for different alpha scaling factors in clayey soils

Table 3. Comparison between measured and estimated moisture contents, analyzed by Arya and Paris (1981) model in clayey soils, based on particle-size analysis obtained by the PSA and BH for three alpha scaling factors evaluated

\begin{tabular}{|c|c|c|c|c|c|c|}
\hline \multirow{2}{*}{ Fitting parameters } & \multicolumn{3}{|c|}{ Particle-size analyzer (PSA) } & \multicolumn{3}{|c|}{ Bouyoucos hydrometer (BH) } \\
\hline & $\alpha 1$ & $\alpha 2$ & $\alpha 3$ & $\alpha 1$ & $\alpha 2$ & $\alpha 3$ \\
\hline Intercept & 0.03354 & 0.06197 & -0.04361 & -0.01118 & 0.09921 & -0.09581 \\
\hline Slope coefficient & 0.75162 & 0.98898 & 1.03536 & 0.90604 & 0.94018 & 1.17596 \\
\hline $\mathrm{R}^{2}$ & 0.5402 & 0.4461 & 0.5565 & 0.6745 & 0.4844 & 0.6091 \\
\hline $\mathrm{RMSE}^{(1)}$ & 0.061 & 0.095 & 0.070 & 0.057 & 0.106 & 0.080 \\
\hline
\end{tabular}

Note. ${ }^{(1)}$ Square root of the mean square error.

\subsubsection{Very Clayey Soils}

For very clayey soils, both in PSA and BH in AP $\times$ R correlations (Figure 5), it was possible to observe the overestimation of values in the low and medium moisture range and underestimation in medium and high ones for the $\alpha 1$ and $\alpha 3$ scaling factors, and mainly overestimation for $\alpha 2$ in practically all moisture range. 


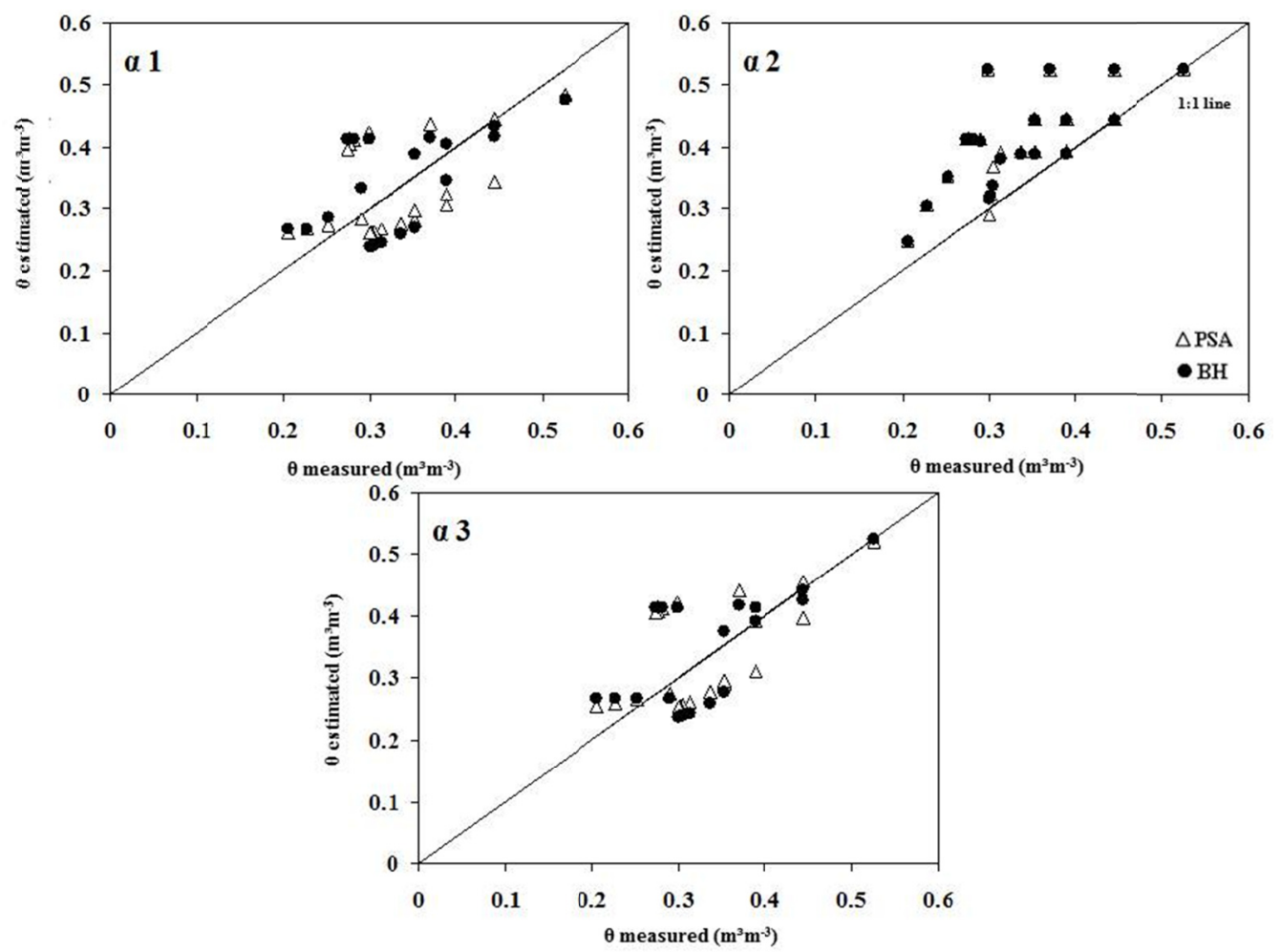

Figure 5. Relationship between measured moisture content $\left(\theta_{\text {measured }}\right) \times$ estimated moisture content $\left(\theta_{\text {estimated }}\right)$ by Arya and Paris (1981) model, based on particle-size analysis determined by the PSA and BH for different alpha scaling factors in very clayey soils

Analyzing all the $a, b$, and RMSE coefficients together (Table 4), similar results were observed for the three scaling factors, considering also that Arya and Paris (1981) model behavior in predicting water retention curve for very clayey soil was lower than the other evaluated soil classes. Such lower result has possibly been influenced by the lower number of evaluated soils for very clayey textural class.

Table 4. Comparison between measured and estimated moisture contents, analyzed by Arya and Paris (1981) model in very clayey soils, based on particle-size analysis obtained by the PSA and BH for three alpha scaling factors evaluated

\begin{tabular}{|c|c|c|c|c|c|c|}
\hline \multirow{2}{*}{ Fitting parameters } & \multicolumn{3}{|c|}{ Particle-size analyzer (PSA) } & \multicolumn{3}{|c|}{ Bouyoucos hydrometer (BH) } \\
\hline & $\alpha 1$ & $\alpha 2$ & $\alpha 3$ & $\alpha 1$ & $\alpha 2$ & $\alpha 3$ \\
\hline Intercept & 0.17006 & 0.17500 & 0.11629 & 0.1896 & 0.2282 & 0.1414 \\
\hline Slope coefficient & 0.49080 & 0.70281 & 0.67323 & 0.4507 & 0.5225 & 0.5949 \\
\hline $\mathrm{R}^{2}$ & 0.2545 & 0.4854 & 0.3797 & 0.274 & 0.3991 & 0.3910 \\
\hline $\operatorname{RMSE}^{(1)}$ & 0.074 & 0.097 & 0.070 & 0.084 & 0.099 & 0.078 \\
\hline
\end{tabular}

Note. ${ }^{(1)}$ Square root of the mean square error.

\subsubsection{All Evaluated Soils (Sandy, Loamy, Clayey, and Very Clayey)}

Analyzing together all evaluated soils (sandy, loamy, clayey, and very clayey), in both PSA and BH of AP $\times$ R correlations (Figure 6), it was possible to observe the predominance of underestimated values for $\alpha 1$ and $\alpha 3$ scaling factors in all moisture contents of the curve, and predominance of overestimation for $\alpha 2$. 

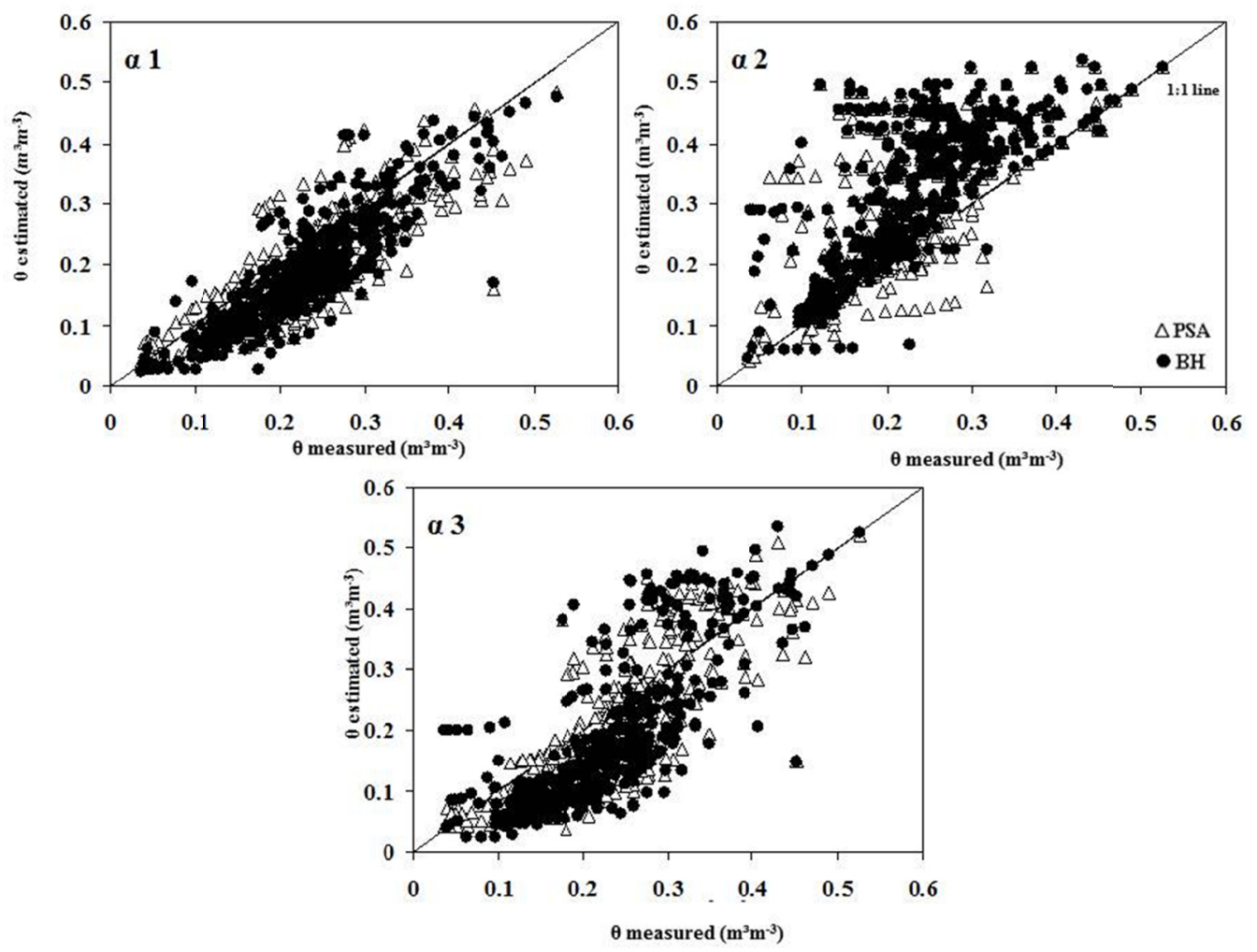

Figure 6. Relationship between measured moisture content $\left(\theta_{\text {measured }}\right) \times$ estimated moisture content $\left(\theta_{\text {estimated }}\right)$ by Arya and Paris (1981) model, based on particle-size analysis determined by the PSA and BH for different alpha scaling factors, considering all evaluated soils (sandy, loamy, clayey, and very clayey textures)

The $a$ and RMSE coefficient values were closer to 0 and the $b$ coefficient were closer to 1 for $\alpha 1$ scaling factor, mainly for soil particle-size data obtained by BH (Table 5), indicating good results of AP model in water retention prediction in all evaluated soils and for scaling factor $\alpha$ 1. Similar results occurred for $\alpha 3$ scaling factor, with best performance for soil particle-size data obtained by the PSA method.

Arya, Bowman, Thapa, \& Cassel (2008) obtained values based on empirical parameters, where there was a difference of $+/-10 \%$ of the best fit values. Data improved significantly when an average value was established for the evaluated parameters, so the differences between the curves practically disappeared.

Table 5. Comparison between measured and estimated moisture contents, analyzed by Arya and Paris (1981) model for all evaluated soils (sandy, loamy, clayey, and very clayey), based on particle-size analysis obtained by the PSA and BH for three alpha scaling factors evaluated

\begin{tabular}{|c|c|c|c|c|c|c|}
\hline \multirow{2}{*}{ Fitting parameters } & \multicolumn{3}{|c|}{ Particle-size analyzer (PSA) } & \multicolumn{3}{|c|}{ Bouyoucos hydrometer (BH) } \\
\hline & $\alpha 1$ & $\alpha 2$ & $\alpha 3$ & $\alpha 1$ & $\alpha 2$ & $\alpha 3$ \\
\hline Intercept & -0.0014 & 0.0973 & -0.0384 & -0.031 & 0.1073 & -0.0531 \\
\hline Slope coefficient & 0.8418 & 0.9165 & 1.0256 & 0.9517 & 0.9169 & 1.0458 \\
\hline $\mathrm{R}^{2}$ & 0.6936 & 0.4419 & 0.6436 & 0.7658 & 0.4959 & 0.5884 \\
\hline $\operatorname{RMSE}^{(2)}$ & 0.063 & 0.119 & 0.074 & 0.063 & 0.1201 & 0.088 \\
\hline
\end{tabular}

Note. ${ }^{(1)}$ Square root of the mean square error.

\section{Conclusions}

(1) Arya-Paris model showed better soil water retention curve predictions for sandy soils, followed by clayey, loamy, and very clayey.

(2) Good behavior of Arya-Paris model was observed when all the soils were considered together. 
(3) The $\alpha 1$ scaling factor provided better predictions, followed by $\alpha 3$ factor, with $\alpha 2$ factor showing unsatisfactory behavior.

(4) Predictions made with soil particle-size data obtained by the Bouyoucos' hydrometer method, using only 7 soil particle-size fractions, were slightly higher than those performed with particle-size analyzer data using 30 soil particle-size fractions.

\section{References}

Arya, L. M., \& Paris, J. F. (1981). A physicoempirical model to predict soil moisture characteristics from particle-size distribution and bulk density data. Soil Science Society of America Journal, 45, 1023-1030. https://doi.org/10.2136/sssaj1981.03615995004500060004x

Arya, L. M., \& Dierolf, T. S. (1992). Predicting soil moisture characteristics from particle-size distributions: An improved method to calculate pore radii from particle radii. In M.Th. van Genuchten, F. J. Leij, \& L. J. Lund (Eds.), Indirect methods for estimating the hydraulic properties of unsaturated soils (pp. 115-124). Univ. of California, Riverside.

Arya, L. M., Leij, F. J., Van Genuchten, M. T., \& Shouse, P. J. (1999). Scaling parameter to predict the soil water characteristic from particle-size distribution data. Soil Science Society of America Journal, 63, 510-519. https://doi.org/10.2136/sssaj1999.03615995006300030013x

Arya, L. M., Bowman, D. C., Thapa, B. B., \& Cassel, D. K. (2008). Scaling soil water characteristics of golf course and athletic field sands from particle-size distribution. Soil Science Society of America Journal, 72, 25-31. https://doi.org/10.2136/sssaj2006.0232

Arya, L. M., \& Heitman, J. L. (2015). A non-empirical method for computing pore radii and soil water characteristics from particle-size distribution. Soil Science Society of America Journal, 79, 1537-1544. https://doi.org/10.2136/sssaj2015.04.0145

Basile, A., \& D’Urso, G. (1997). Experimental corrections of simplified methods for predicting water retention curves in clay-loamy soils from particle-size determination. Soil Technology, 10, 261-272. https://doi.org/ 10.1016/S0933-3630(96)00020-7

Botula, Y. D., Cornelis, W. M., Baert, G., Mafuka, P., \& Ranst, E. (2013). Particle size distribution models for soils of the humid tropics. Journal of Soils and Sediments, 13, 686-698. https://doi.org/10.1007/s11368012-0635-5

Carrick, S., Buchan, G. D., Almond, P., \& Smith, N. (2011). A typical early-time infiltration into a structured soil near field capacity: The dynamic interplay between sorptivity, hydrophobicity, and air encapsulation. Geoderma, 160, 579-589. https://doi.org/10.1016/j.geoderma.2010.11.006

Chiu, C. F., Yan, W. M., \& Ka-Veng, Y. (2012). Estimation of water retention curve of granular soils from particle-size distribution-A Bayesian probabilistic approach. Can. Geotech, 49, 1024-1035. https://doi.org/ $10.1139 / \mathrm{t} 2012-062$

Donagema, G. K., Campos, D. V. B. De, Caldeerano, S. B., Teixeira, W. G., \& Viana, J. H. M. (2011). Manual de métodos de análise do solo (2nd ed., p. 230). Rio de Janeiro: Embrapa Solos.

Dourado-Neto, D., Nielsen, D. R., Hopmans, J. W., Reichardt, K., \& Bacchi, O. O. S. (2000). Programa computacional para modelagem de curvas de retenção de água no solo (SWRC, versão 2.00). Sciencia Agricola, Piracicaba, 57(1), 191-192. https://doi.org/10.1590/S0103-90162000000100031

Fooladmand, H. R., \& Habibi, M. (2012). Estimating soil water characteristic curve based on soil particle-size distribution curve and local void ratio. African J. Agric. Res., 7, 2197-204.

Hwang, S., \& Choi, S. (2006). Use of a lognormal distribution model for estimating soil water retention curves from particle-size distribution data. Journal of Hydrology, 323, 325-334. https://doi.org/10.1016/j.jhydrol. 2005.09.005

Matula, S., Mojrova, M., \& Spongrova, K. (2007). Estimation of the water retention curve (SWRC) using pedotransfer functions (PTFs). Soil Water Res., 2, 113-122. https://doi.org/10.17221/2106-SWR

Meskini-Vishkaee F., Mohammadi, M. H., \& Vanclooster, M. (2014). 435 Predicting the soil moisture retention curve, from soil particle size distribution and bulk density data using a packing density scaling factor. Hydrology and Earth System Science, 18. https://doi.org/10.5194/hess-18-4053-2014 
Minasny, B., \& Hartemink, A. E. (2011). Predicting soil properties in the tropics. Earth Sci Rev., 106, 52-62. https://doi.org/10.1016/j.earscirev.2011.01.005

Mohammadi, M. H., Neishabouri, M. R., \& Rafahi, H. (2009). Predicting the solute breakthrough curve from soil hydraulic properties. Soil Sci., 174, 165-173. https://doi.org/10.1097/SS.0b013e3181998fa7

Mohammadi, M. H., Asadzadeh, F., \& Vanclooster, M. (2010). Refining and unifying the upper limits of the least limiting water range using soil and plant properties. Plant Soil, 334, 221-234. https://doi.org/10.1007/s111 04-010-0377-3

Mohammadi, M. H., \& Vanclooster, M. (2011). Predicting the soil moisture characteristic curve from particle size distribution with a simple conceptual model. Vadose Zone J., 10, 594-602. https://doi.org/10.2136/ vzj2010.0080

Mohamaadi, M. H., \& Meskini-Vishkaee. (2013). Predicting soil moisture characteristic curves from continuous particle-size distribution data. Soil Science Society of China, 23, 70-80. https://doi.org/10.1016/S10 02-0160(12)60081-2

Naime, J. M., Vaz, C. M. P., \& Macedo, Á. (2001). Automated soil particle analyzer based on gamma-ray attenuation. Comput. Electron. Agr., 31, 295-304. https://doi.org/10.1016/S0168-1699(00)00188-5

Nascimento, P. dos S., Bassoi, L. H., \& Paz, V. P. da S. (2012). Planilha eletrônica para auxilio à tomada de decisão em manejo de irrigação. Irriga, 17, 1-15. https://doi.org/10.15809/irriga.2012v17n1p01

Nimmo, J. R., Herkelrath, W. N., \& Laguna Luna, A. M. (2007). Physically based estimation of soil water retention from textural data: General framework, new models, and streamlined existing models. Vadose Zone J., 6, 766-773. https://doi.org/10.2136/vzj2007.0019

Pachepsky, Y. A., \& Rawls, W. J. (1999). Accuracy and reliability of pedotransfer functions as affected by grouping soils. Soil Science Society of America Journal, 63(6), 1748-1757. https://doi.org/10.2136/sssaj $1999.6361748 \mathrm{x}$

Reichardt, K. (1985). Processos de transferência no sistema solo-planta-atmosfera (p. 466). Campinas: Fundação Cargill.

Reichardt, K., \& Timm, L. C. (2004). Solo, planta e atmosfera: conceitos, processos e aplicações (p. 478). Piracicaba: Manole.

Richards, L. A. (1949). Methods of measuring moisture tension. Soil Science, 68, 95-112. https://doi.org/10.109 7/00010694-194907000-00008

Sepaskhah, A. R., \& Raifee, M. R. (2008). Evaluation of scaling parameter to predict soil water characteristic curve using improved particle-size distribution. Iranian J. Sci. Technol. Trans. B Eng., 32, 549-556.

Urach, F. L. (2007). Estimativa da retenção de água em solos para fins de irrigação (p. 79, Dissertação, Mestrado em Engenharia Agrícola, Universidade Federal de Santa Maria, Santa Maria, Brazil). Retrieved from https://repositorio.ufsm.br/handle/1/7593

Van Genuchten, M. T. H. (1980). A closed-form equation for predicting the hydraulic conductivity of unsaturated soils. Soil Science Society of America Journal, 44, 892-898. https://doi.org/10.2136/sssaj1980.03615995 $004400050002 \mathrm{x}$

Vaz, C. M. P., Iossi, M. F., Naime, J. M., Macedo, A., Reichert, J. M., Reinert, D. J., \& Cooper, M. (2005). Validation of the Arya and Paris water retention model for Brazilian soils. Soil Science Society of America Journal, 69, 577-583. https://doi.org/10.2136/sssaj2004.0104

Vieira, M. L. (2007). Propriedades físico-hídrico-mecânicas do solo e rendimento de milho submetido a diferentes sistemas de manejo. Revista Brasileira de Ciência do Solo, 31, 1721-1280.

Wang D., Fu B. J., Zhao W. W., Hu H. F., \& Wang Y. F. (2008). Multifractal characteristics of soil particle size distribution under different land-use types on the Loess Plateau, China. Catena, 72, 29-36. https://doi.org/ 10.1016/j.catena.2007.03.019 


\section{Copyrights}

Copyright for this article is retained by the author(s), with first publication rights granted to the journal.

This is an open-access article distributed under the terms and conditions of the Creative Commons Attribution license (http://creativecommons.org/licenses/by/4.0/). 